\title{
Fault analysis method of integrated high voltage direct current transmission lines for onshore wind farm
}

\author{
Shobha AGARWAL ${ }^{1}$, Aleena SWETAPADMA ${ }^{2}$, Chinmoy PANIGRAHI ${ }^{1}$, \\ Abhijit DASGUPTA ${ }^{1}$
}

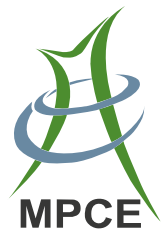

\begin{abstract}
Voltage source converter (VSC) based high voltage direct current (HVDC) transmission is most suited for the wind farm as it allows flexibility for reactive power control in multi-terminal transmission lines and transmits low power over smaller distance. In this work, a novel method has been proposed to detect the fault, identify the section of faults and classify the pole of the fault in DC transmission lines fed from onshore wind farm. In the proposed scheme, voltage signal from rectifier end terminal is extracted with sampling frequency of $1 \mathrm{kHz}$ given as input to the detection, classification and section discrimination module. In this work, severe AC faults are also considered for section discrimination. Proposed method uses fuzzy inference system (FIS) to carry out all relaying task. The reach setting of the relay is $99.9 \%$ of the transmission line. Besides, the protection covers and discriminates the grounding fault with fault resistance up to $300 \Omega$.
\end{abstract}

CrossCheck date: 20 September 2018

Received: 6 November 2017/ Accepted: 20 September 2018/

Published online: 17 December 2018

(C) The Author(s) 2018

$\triangle$ Aleena SWETAPADMA

aleena.swetapadma@gmail.com

Shobha AGARWAL

sobha.agarwalfel@kiit.ac.in

Chinmoy PANIGRAHI

panigrahichinmoy@gmail.com

Abhijit DASGUPTA

dg.abhijit@gmail.com

1 School of Electrical Engineering, KIIT University, Bhubaneswar, India

2 School of Computer Engineering, KIIT University, Bhubaneswar, India
Considering the results of the proposed method it can be used effectively in real power network.

Keywords Voltage source converter based high voltage direct current (VSC-HVDC) transmission lines, Wind farm, Doubly-fed induction generator, Fuzzy inference system (FIS)

\section{Introduction}

Onshore and offshore wind farms are increasing with the recent development in wind energy in the power sector. Maintenance and construction cost is higher for offshore farm than onshore. Wind energy from farms is combined to transmit power through high voltage direct current (HVDC) link. Different methods have been suggested for analysis of faults such as over current protection, current differential protection, under voltage protection, voltage derivative protection [1]. Technical and economical feasibility of voltage source converter (VSC) for offshore wind farm is lower than AC systems as suggested in [2]. VSCHVDC transmission lines can independently control both reactive power and active power and does not require external voltage for its self commutating device. In [3], LCC network usability of static synchronous compensators (STATCOMs) and its feasibility for large off shore wind farms with STATCOM is studied.

The first offshore wind power application on VSC was implemented in Germany is described in [4]. In [5], multi terminal VSC-HVDC link in Norway has been described. In [6], it has been suggested that VSC are preferred for multi terminal DC (MTDC) because power flow can be reversed without changing the polarity of dc link voltage. In weak power system short circuit can be prevented by 
blocking of signals of wind farm converters [7]. In [8], fault study has been done using empirical mode decomposition which requires phasor measurement unit (PMU) or communication network which is very expensive. In [9], it has been discussed that lack of fast clearance of fault resulting in voltage collapsing. In [10], a method has been proposed to block the converters under grid side fault.

In [11], it has been discussed that when a DC link voltage exceeds the threshold value the active power generation is reduced. But it lacks the capability to identify the fault section. In [12], automatic coordination between the converters with different power output has been achieved. But in this work fault under grid side has not been mentioned. In [13], wind turbines using current source inverters are studied by series and parallel connection. But it lacks control of output power of wind farm. The limitations of [13] are overcome in [14] by using VSC with DC link. In [15], permanent magnet synchronous generators (PMSG) wind turbines (WTs) are modeled. But the magnetic materials are susceptible to temperature and effect of temperature on PMSG under fault condition is not discussed. The method also requires communication link and fault in wind farm side have not been discussed. In [16], fault ride through capability has been increased by using nine switches in grid side converter but it does not carry out the section identification task. In [17], a travelling wave protection scheme has been used for section identification but it requires communication link for detecting faults which may causes delay and increase cost.

In [18], support vector machine (SVM) has been used for fault detection but it has the demerits of large training data and more memory requirements. The limitations of method suggested in [19] are that it requires large training data and AC section faults are not realized. Several artificial intelligence (AI) techniques are used for $\mathrm{AC}$ lines $[20,21]$ but detection of fault in DC lines from onshore wind has not been discussed. Four-terminal HVDC system during wind speed and power variations with onshore grid faults has been discussed in [22]. It focused on fault ride through capability and not on section identification. Wavelet techniques suggested in [23] for wind farm protection requires high sampling frequency which is practically difficult to analyze. It also depends on information from both ends of line. It uses detail coefficients which has the disadvantage of small standard deviation [23]. In [24-26], detailed modeling of doubly-fed induction generator (DFIG) has been studied. Its properties are compared with asynchronous and synchronous machines. In [27], a protection system for multi-terminal system based on the supplemental inductor placed at both ends of the DC line has been proposed. Drawback of the scheme is that main protection may not identify the high-resistance faults.
Hence back up protection is required which needs data from both ends.

In [28], a protection scheme using the rate of change of voltage measured at the line side of the limiting reactors has been proposed. The method has not been tested for high fault resistance or varying resistances. In [29], fault detection has been analysed from short-circuit current (SCC) or current flowing through fault period and temporary over voltage or highest recovery voltage during post fault. In [30], an artificial neural network (ANN) method for multi-terminal HVDC protection relaying has been suggested which uses sampling frequency of $10 \mathrm{kHz}$. It cannot detect fault which has resistance higher than $100 \Omega$. In [31], application of multilevel full bridge converters in HVDC multiterminal systems has been proposed. Therefore, reliability and selectivity of the system depends on all the parameters. In [32], a method has been proposed in which the relay embedded into each converter sends a trip signal to the rectifier to identify the fault whenever over current is above a threshold. Drawback of the method is that it has not been tested for varying conditions of fault resistance and it uses high sampling frequency. In [33], a protection scheme has been proposed based on the time coordination of constant delay time distance relay and over current distance relay. This coordination causes delay in detection and mal-operation can cause severe damage to the network. In [34], protection scheme for multiterminal DC compact node feeding electric vehicles on electric railway systems, secondary distribution networks, and photovoltaic (PV) systems has been proposed. In this scheme AC section fault has not been considered for section discrimination.

In [35], line faults component of current network with voltage at the source point has been used for identification of section at low and high frequency based on impedance. The time for fault detection is more than $20 \mathrm{~ms}$, sampling frequency is $10 \mathrm{kHz}$ and fault resistance used is $200 \Omega$. In [36], a method has been proposed in which the input signals uses five data window having rms three phase input voltages and time averaged DC voltage and current of DC transmission lines with sampling frequency of $4 \mathrm{kHz}$ and fault resistance identification is limited below $100 \Omega$ and average time for responding is $3 / 4$ of a cycle. In [37], a method is selected based on natural frequency of travelling wave for fault section detection. This scheme based on distance and reflection coefficient of current signal with high sampling frequency $100 \mathrm{kHz}$. In [38], a method for two terminal system based on wavelet coefficients of current and rate of change of current has been chosen for detection of fault. In this method high fault resistance is not taken and sampling frequency is $10 \mathrm{kHz}$. In [39], a section identification method has been proposed based on transverse differential current using the ratio of difference and 
sum current of pole 1 (P1) and pole 2 (P2). Besides the fault resistance is limited up to $50 \Omega$. In [40], a method based on current signal using discrete wavelet coefficients of signal for different levels has been proposed to detect the fault which has high sampling frequency of $10 \mathrm{kHz}$. In [41], pole to ground fault characteristics analysis on dc transmission line is studied.

Considering the merits and demerits of the above described works, a fuzzy based method has been implemented based on advantages of VSC converters and DFIG wind farms. Added merits of fuzzy reasoning are that it has a natural language for communication with human and capable of tolerating imprecise data. Some of the conventional protection schemes like distance relay method suited for AC systems but not for DC due to its low impedance. The main benefits of the proposed scheme is that it uses single relay at the rectifier end to trip under all internal faults and isolate the external fault. The response of the grid side fault is not same as wind farm side fault. Discrimination of both fault and selective tripping has been achieved in the proposed work. Grid side faults are very common. If these faults occur then relay at the AC section of grid side will initiate the trip command. If some temporary fault occurs in wind farm section then the effects are not reflected in DC section. Fuzzy logic approach is appropriate for this problem as one DC section and two AC section whose features under fault are not precisely distinct under various condition.

The proposed paper is structured as follows. Section 2 outlines wind farm energy system. Section 3 contains the fault analysis and input signal feature extraction. Section 4 contains the flowchart and simulation scheme. Section 5 describes the test results and merits of the result. Section 6 is the conclusion of the work.

\section{Wind farm energy system}

Wind energy conversion system includes the onshore WT, DFIG of high rating, transformers, neutral point clamped (NPC) VSC and bipolar HVDC link. For a wind turbine, the output power $P_{m}$ of the turbine can be given in (1).

$P_{m}=\frac{1}{2} \rho A c_{p}(\lambda, \beta) v_{\mathrm{w}}^{3}$

$\lambda=\frac{R w}{v_{\mathrm{w}}}$

where $\rho$ is the air density $\left(1.25 \mathrm{~kg} / \mathrm{m}^{2}\right) ; A$ is the rotor swept area; $c_{p}$ is the turbine efficiency; $\lambda$ is the turbine tip speed ratio; $\beta$ is the pitch angle of the turbine; $R$ is the blade length; $v_{\mathrm{w}}$ is the actual speed of the wind; $w$ is the speed of rotation of $d q$ reference frame. Power extracted/rotational speed of turbine blades, $T_{m}$ is given as:

$T_{m}=\frac{1}{2 \lambda} \rho \pi c_{p} R^{3} v_{\mathrm{w}}^{2}$

DFIG has been proposed for wind farms because $\pm 30 \%$ variable speed is possible without drawing excessive reactive power under grid voltage dip [25]. DC overhead transmission lines of around $300 \mathrm{~km}$ are considered for simulation in MATLAB/Simulink. Three phase transformer of rating $25000 / 575 \mathrm{~V}$ are connected for stepping up the voltage of wind turbine with primary connected in delta and secondary in star with primary lagging by an angle of $30^{\circ}$ and another transformer with rating of $230 / 25 \mathrm{kV}$ with primary connected in delta and secondary in star after short transmission line of $20 \mathrm{~km}$ length for increasing the voltage. Power system network have been studied and its waveforms are shown in Fig. 1. The simulation results for DC link voltages are shown in Fig. 1a. Figure 1b shows the turbine speed and Fig. 1c shows the active power. Figure 1d shows the reactive power output of for 36 wind turbines in a wind farm. The faults scenarios are also analyzed which will be described in next section.

\section{Analysis of faults}

In this section faults occurring in the overhead DC transmission line and $\mathrm{AC}$ faults for wind farms and grid, side is studied. Various types of DC transmission line faults

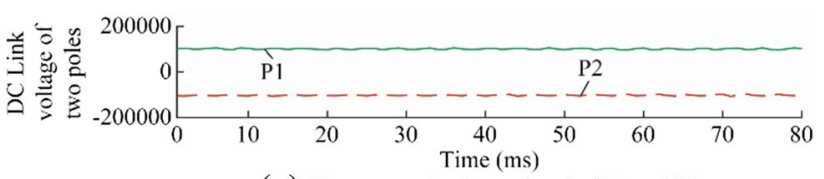

(a) Unprocessed voltage signal of P1 and P2

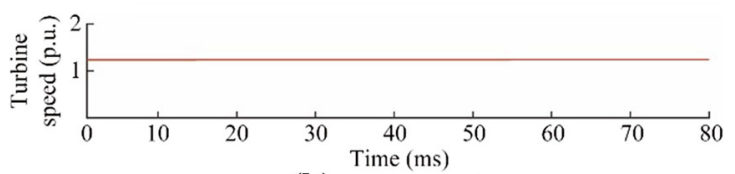

(b) Turbine speed

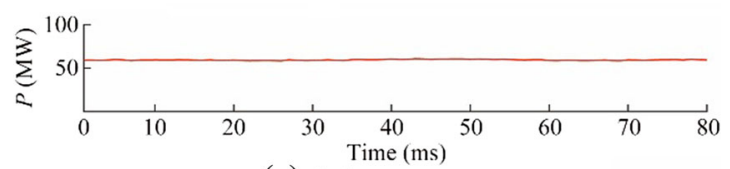

(c) Active power output

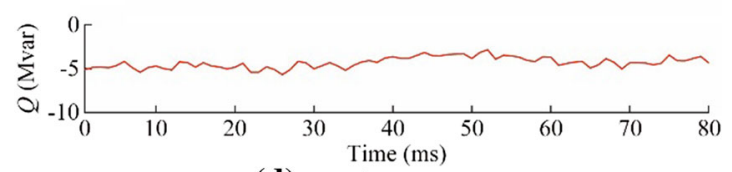

(d) Reactive power output

Fig. 1 Voltage signal, turbine speed, active power output, reactive power output of 36 wind turbines in a wind farm 
and $\mathrm{AC}$ side faults are shown in Fig. 2. P1 to ground faults is shown in the Fig. 2a and P2 to ground faults is shown in the Fig. 2b. Pole to pole to ground fault is shown in Fig. 2c. In Fig. 2d, AC faults in grid side near inverter end are shown. In Fig. 2e, AC faults in wind farm side near rectifier end are shown. Reversal of power flow is an important feature of VSC-HVDC system. The advantage of reversal of power is achieved through reversal of current. Hence the parameter selected for fault analysis is voltage as it is not affected by the reversal of power. Analysis of various faults and method suggested to detect the faults are described in the next section.

\section{Proposed method}

Fault characteristics of voltage signals are obtained from DC section and AC section fault for design of fuzzy inference system (FIS). Various steps followed to design FIS are pre-processing, fuzzification, rule base, inference engine, defuzzification and post processing. The inputs are most often hard or crisp measurements rather than linguistic. Pre-processor conditions the measurements before it enter the controller. Fuzzification converts each piece of input data to degrees of membership.

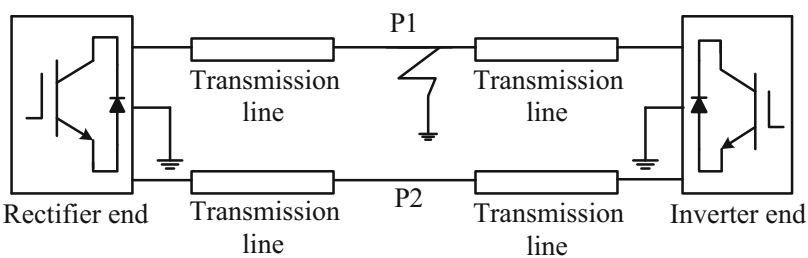

(a) P1 to ground fault (P1G)

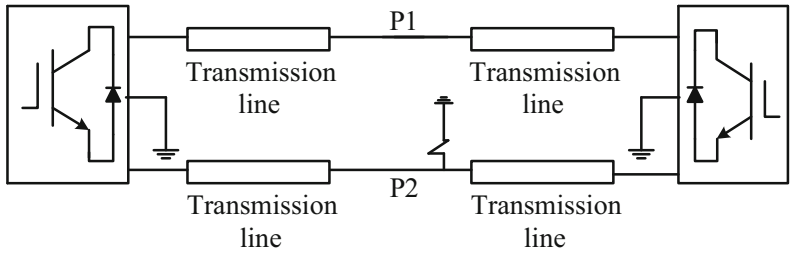

(b) P2 to ground fault (P2G)

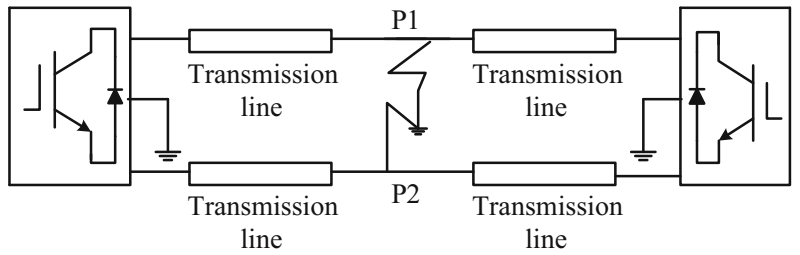

(c) Double pole to ground fault (P1P2G)

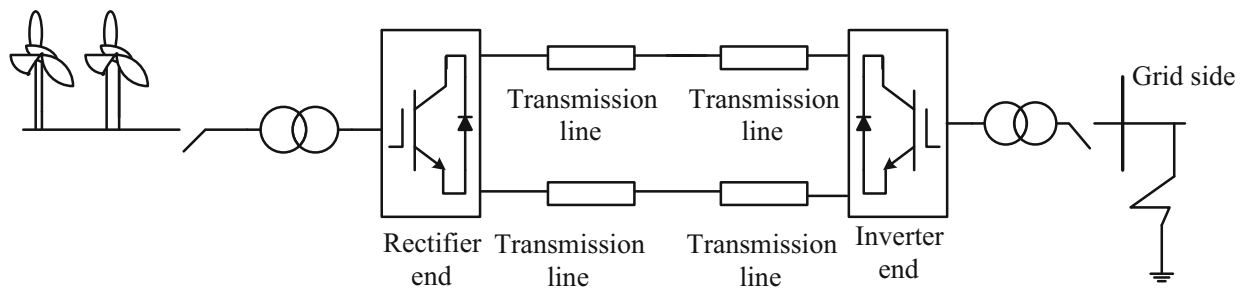

(d) Grid side AC fault

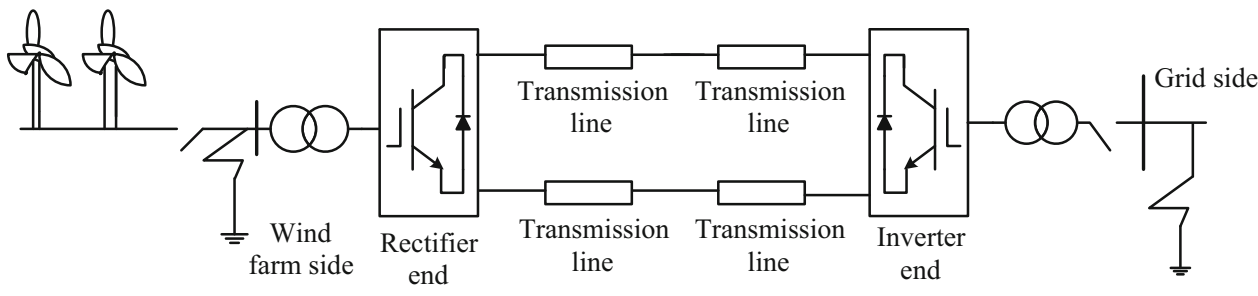

(e) Faults in wind farm side

Fig. 2 Faults in AC and DC section of line 
The fuzzification block matches the input data with the conditions of the rules to determine how well the condition of each rule matches that particular input instance. There is a degree of membership for each linguistic term that applies to that input variable. Linguistic controller contains rules in if-then format. The rules reflect the strategy that the control signal should be a combination of the reference error and the change in error, a fuzzy proportionalderivative controller. For each rule, the inference engine looks up the membership values in the condition of the rule. The aggregation operation is used when calculating the degree of fulfilment or firing strength. The activation of a rule is the deduction of the conclusion reduced by its firing strength. Min or product is used as the activation. All activated conclusions are accumulated using the max operation. The resulting fuzzy set must be converted to a number that can be sent to the process as a control signal called defuzzification. There are several defuzzification methods from which centre of gravity is used in this work. The post processing block often contains an output gain that can be tuned.

In Fig. 3, the flowchart of the proposed method has been presented. The DC voltage signals are obtained from the rectifier end of the circuit and are processed by taking root mean square of the voltage signals. The processed input voltage signals obtained from relaying point are used as

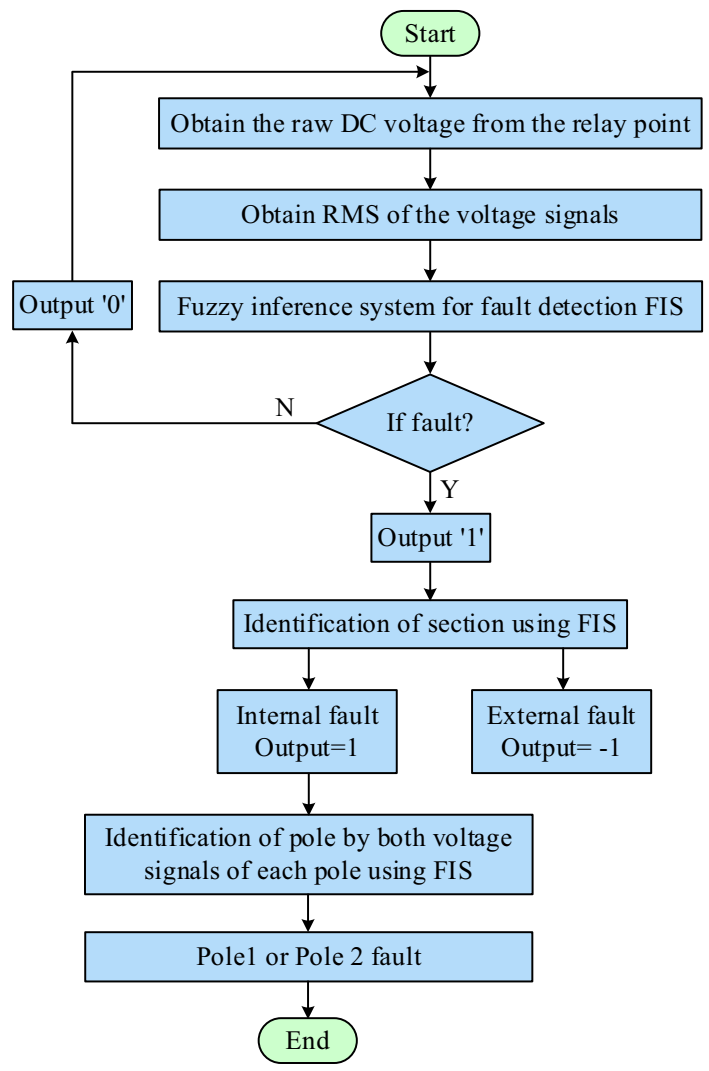

Fig. 3 Flowchart of the proposed method crisp input to the FIS. In this work same input membership function is used with different sets of rules for faults detection, discrimination of fault section and classification of fault pole. The FIS is designed such that output of fault detection is ' 1 ' if there is any fault. The output is ' 0 ' for no fault. After detection of faults output of section identification FIS should be ' 0 ', ' 1 ' and ' -1 ' for no fault, a fault in DC section and faults in AC section. The output of fault in $\mathrm{P} 1$ and $\mathrm{P} 2$ is ' 1 ' and ' 0 ' then fault pole is $\mathrm{P} 1$ and vice versa.

\subsection{Design of fault detection module}

In this work a fuzzy based module is designed for fault detection. The FIS used in this work is 'Mamdani' type. The implication method used is minimum, aggregation method used is maximum and defuzzification method used is centroid. The membership functions used to design the inputs and outputs are triangular member function. Processed voltage signals from rectifier end are extracted and the membership function ranges are set using the voltage signals. Using triangular membership function three ranges are selected $V_{\mathrm{LOW}}, V_{\mathrm{MID}}$ and $V_{\mathrm{HIGH}}$ for processed signals. The membership functions of the crisp input signals are shown in Fig. 4. In DC section fault voltage signal decreases and in wind farm side $\mathrm{AC}$ fault the voltage signal decreases after the fault but AC fault in grid side causes voltages rises little or more with the fault. The outputs of fault detection are TR(1) for faults and $\mathrm{TN}(0)$ for no faults. The rules designed for fault detection module are given below.

1) If input is $V_{\text {LOw }}$ then $\operatorname{TR}(1)$.

2) If input is $V_{\text {MID }}$ then $\mathrm{TN}(0)$.

3) If input is $V_{\mathrm{HIGH}}$ then $\mathrm{TR}(0)$.

\subsection{Design of fault section discrimination module}

In this work, a FIS is designed for fault section identification. Fault discrimination is carried out from wind farm

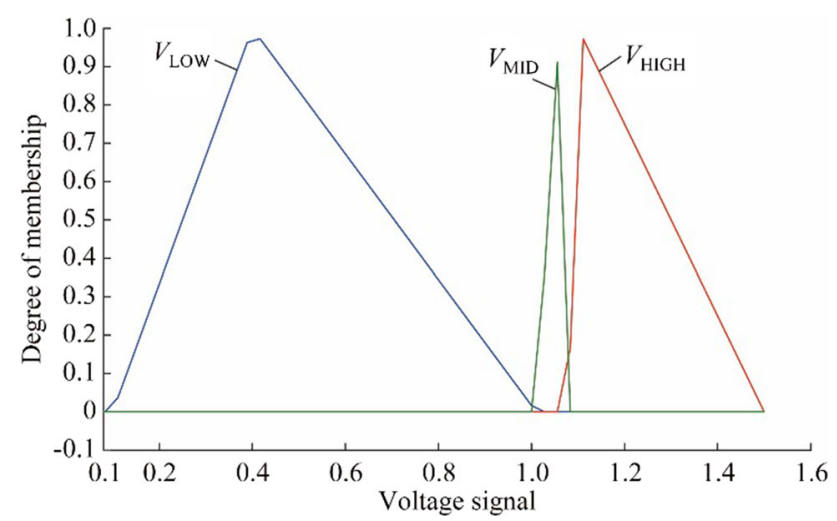

Fig. 4 Membership functions used for fault detection, fault section identification and fault pole identification 


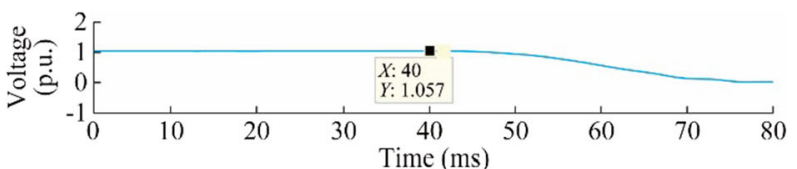

(a) Voltage signals of P1

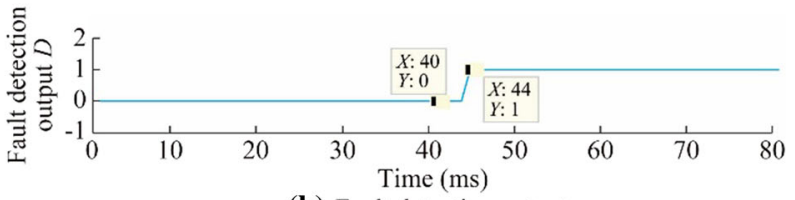

(b) Fault detection output
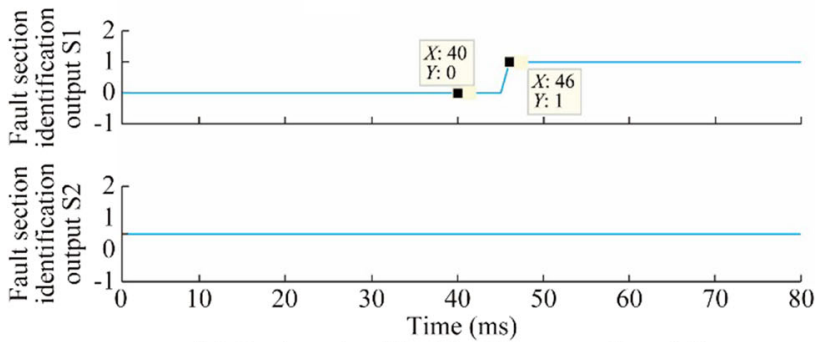

(c) Fault section identification output S1 and S2
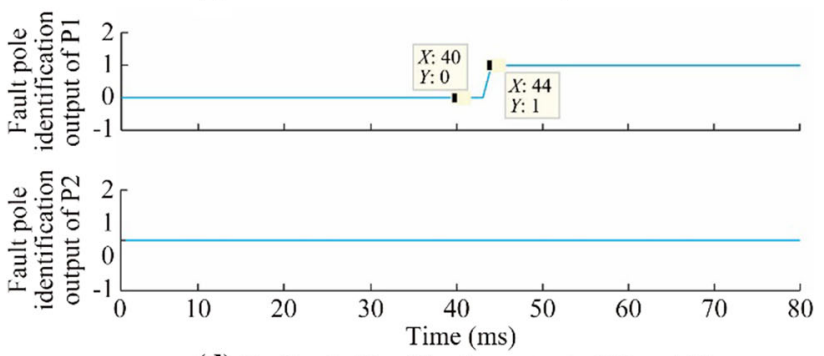

(d) Fault pole identification output of P1 and P2

Fig. 5 Voltage signal, fault detection output, fault section identification output, fault pole identification output during P1G fault for the location of $1 \mathrm{~km}$ at fault resistance of $0 \Omega$

Table 1 Parameters used for testing

\begin{tabular}{ll}
\hline Parameters & Values \\
\hline Fault location in DC lines & 1 to $299 \mathrm{~km}$ in the step of $2 \mathrm{~km}$ \\
Fault location in DC lines & 1 to $19 \mathrm{~km}$ in the step of $1 \mathrm{~km}$ \\
Fault type in DC & P1G, P2G, P1P2G, P1P2 \\
Faults in grid side & L-G, LL-G, LL, LLL-G, LLL \\
Fault resistance & 0 to $300 \Omega$ \\
Faults in grid side & L-G, LL-G, LL, LLL-G, LLL \\
Close-in faults & 0.1 to $5 \mathrm{~km}$
\end{tabular}

Note: L-G (line to ground), LL-G (double line to ground), LL (line to line), LLL (triple line) and LLL-G (triple line to ground)

end $\mathrm{AC}$ section to DC section and grid fault section to DC section. The input membership functions are same as designed for fault detection module. The outputs are $\mathrm{TR}(-1)$ for faults in $\mathrm{AC}$ section, TR(1) for DC section and $\mathrm{TN}(0)$ for no faults. Rules designed for fault section identification are given below.
1) If both input are $V_{\mathrm{LOW}}$ then $\mathrm{TR}(-1)$.

2) If input 1 is $V_{\text {MID }}$ and input 2 is $V_{\text {MID }}$ then $\mathrm{TN}(0)$.

$3)$ If input 1 is $V_{\text {MID }}$ and input 2 is $V_{\text {LOW }}$ then $\operatorname{TR}(1)$.

4) If input 1 is $V_{\text {LOW }}$ and input 2 is $V_{\text {MID }}$ then $\operatorname{TR}(1)$.

5) If input 1 is $V_{\mathrm{HIGH}}$ and input 2 is $V_{\mathrm{MID}}$ then $\mathrm{TN}(0)$.

6) If input 1 is $V_{\mathrm{HIGH}}$ and input 2 is $V_{\text {LOW }}$ then $\operatorname{TR}(1)$.

7) If input 1 is $V_{\text {LOW }}$ and input 2 is $V_{\mathrm{HIGH}}$ then $\mathrm{TR}(1)$.

8) If input 1 is $V_{\mathrm{MID}}$ and input 2 is $V_{\mathrm{HIGH}}$ then $\mathrm{TN}(0)$.

9) If both the inputs are $V_{\mathrm{HIGH}}$ then $\mathrm{TN}(0)$.

\subsection{Design of fault pole identification module}

In this work an FIS is designed for fault pole identification. The input membership functions are same as designed for fault detection module. The outputs are TR(1) for fault poles and $\mathrm{TN}(0)$ for non fault poles. Input membership functions for fault pole identification scheme are shown in Fig. 4. Rules used for classification of faults are given as:

1) If input 1 is $\mathrm{V}_{\mathrm{HIGH}}$ and input 2 is $\mathrm{V}_{\mathrm{LOW}}$ then $\mathrm{TN}(0)$ for $\mathrm{P} 1$ and TR(1) for P2.

2) If input 2 is $V_{\mathrm{HIGH}}$ and input 1 is $\mathrm{V}_{\mathrm{LOW}}$ then $\mathrm{TN}(0)$ for $\mathrm{P} 2$ and TR(1) for P1.

3) If the input 1 is $\mathrm{V}_{\mathrm{HIGH}}$ and input 2 is $\mathrm{V}_{\mathrm{HIGH}}$ then $\mathrm{TN}(0)$ for $\mathrm{P} 1$ and $\mathrm{TN}(0)$ for $\mathrm{P} 2$.

\section{Results and discussions}

The performance of the proposed fuzzy based fault scheme is estimated and the results are analysed. Various parameters have been considered for testing the proposed method. All the parameters used for testing are given in Table 1. Some simulation results of the proposed method are discussed below.

\subsection{Performance varying close-in faults}

The proposed scheme is tested for close-in faults up to $5 \mathrm{~km}$ of line. One of the test results at location of $1 \mathrm{~km}$ and fault resistance $0 \Omega$ is shown in Fig. 5 during P1G fault. Figure 5a shows processed voltage for fault at 40 $\mathrm{ms}$ in the pole1. Voltage signal of the faulty pole decreases after the fault if not detected will leads to collapsing of poles. In Fig. 5b, fault detection output $D$ is shown which become ' 1 ' after $44 \mathrm{~ms}$ from instant of fault shows there is a fault in the system. Figure $5 \mathrm{c}$ shows the output of fault section output. Output in DC section (S1) is ' 1 ' at $46 \mathrm{~ms}$ but output in AC section (S2) remains ' 0 ' indicate fault is in DC section of line. Figure $5 \mathrm{~d}$ shows the output of fault pole identification. Output of P1 is ' 1 ' at $44 \mathrm{~ms}$ but output of $\mathrm{P} 2$ remains ' 0 ' indicate fault is in 
Table 2 Performance varying close-in faults (fault type is P1G)

\begin{tabular}{|c|c|c|c|c|c|c|c|}
\hline \multirow[t]{3}{*}{ Position $(\mathrm{km})$} & \multicolumn{2}{|c|}{ Fault detection } & \multicolumn{4}{|c|}{ Fault section identification } & \multirow[t]{3}{*}{ Identification } \\
\hline & \multirow[t]{2}{*}{ Output } & \multirow[t]{2}{*}{ Time (ms) } & \multicolumn{2}{|l|}{ S1 } & \multicolumn{2}{|l|}{$\mathrm{S} 2$} & \\
\hline & & & Output & Time (ms) & Output & Time (ms) & \\
\hline 1 & 1 & 4 & 1 & 6 & 0 & - & Internal fault \\
\hline 2 & 1 & 4 & 1 & 6 & 0 & - & Internal fault \\
\hline 3 & 1 & 4 & 1 & 6 & 0 & - & Internal fault \\
\hline 4 & 1 & 5 & 1 & 6 & 0 & - & Internal fault \\
\hline 5 & 1 & 5 & 1 & 6 & 0 & - & Internal fault \\
\hline
\end{tabular}

Table 3 Performance varying far end faults

\begin{tabular}{|c|c|c|c|c|c|c|c|c|}
\hline \multirow[t]{3}{*}{ Fault type } & \multirow[t]{3}{*}{ Position (km) } & \multicolumn{2}{|c|}{ Fault detection } & \multicolumn{4}{|c|}{ Fault section identification } & \multirow[t]{3}{*}{ Identification } \\
\hline & & \multirow[t]{2}{*}{ Output } & \multirow[t]{2}{*}{ Time (ms) } & \multicolumn{2}{|l|}{ S1 } & \multicolumn{2}{|l|}{ S2 } & \\
\hline & & & & Output & Time (ms) & Output & Time (ms) & \\
\hline \multirow[t]{3}{*}{$\mathrm{P} 1 \mathrm{G}$} & 291 & 1 & 6 & 1 & 7 & 0 & - & Internal fault \\
\hline & 292 & 1 & 7 & 1 & 7 & 0 & - & Internal fault \\
\hline & 293 & 1 & 8 & 1 & 8 & 0 & - & Internal fault \\
\hline \multirow[t]{3}{*}{$\mathrm{P} 2 \mathrm{G}$} & 294 & 1 & 8 & 1 & 9 & 0 & - & Internal fault \\
\hline & 295 & 1 & 8 & 1 & 8 & 0 & - & Internal fault \\
\hline & 296 & 1 & 9 & 1 & 9 & 0 & - & Internal fault \\
\hline
\end{tabular}

Table 4 Performance varying fault resistance

\begin{tabular}{|c|c|c|c|c|c|c|c|c|c|}
\hline \multirow[t]{3}{*}{ Fault type } & \multirow[t]{3}{*}{$R(\Omega)$} & \multirow[t]{3}{*}{ Position (km) } & \multicolumn{2}{|c|}{ Fault detection } & \multicolumn{4}{|c|}{ Fault section identification } & \multirow[t]{3}{*}{ Identification } \\
\hline & & & \multirow[t]{2}{*}{ Output } & \multirow[t]{2}{*}{ Time (ms) } & \multicolumn{2}{|l|}{ S1 } & \multicolumn{2}{|l|}{ S2 } & \\
\hline & & & & & Output & Time (ms) & Output & Time (ms) & \\
\hline \multirow[t]{3}{*}{ P1G } & 100 & 50 & 1 & 7 & 1 & 7 & 0 & - & Internal fault \\
\hline & 200 & 80 & 1 & 8 & 1 & 9 & 0 & - & Internal fault \\
\hline & 300 & 110 & 1 & 10 & 1 & 11 & 0 & - & Internal fault \\
\hline \multirow[t]{3}{*}{$\mathrm{P} 2 \mathrm{G}$} & 100 & 200 & 1 & 12 & 1 & 13 & 0 & - & Internal fault \\
\hline & 200 & 230 & 1 & 14 & 1 & 15 & 0 & - & Internal fault \\
\hline & 300 & 260 & 1 & 15 & 1 & 16 & 0 & - & Internal fault \\
\hline
\end{tabular}

pole1. Some of the test results of proposed method are shown in Table 2. It can be observed from the table that proposed method detect and identify the section of fault correctly in case of close-in faults.

\subsection{Performance varying far end faults}

Most of the protection schemes fail to detect the fault at far end. In transmission lines far end faults with high fault resistance are difficult to detect and thus circuit breaker fails to trip. The proposed schemes have been tested for far end faults 280-299 km of line. Some of the test results of proposed method during far end faults are shown in Table 3. It can be observed from the table that proposed method detect and identify the section of fault correctly in case of far end faults.

\subsection{Performance varying fault resistance}

The proposed method has also been tested varying fault resistance up to $300 \Omega$. Some of the test results of high fault resistance are given in Table 4. From Table 4, it can 
be observed that proposed method can detect faults, identify the section of the fault and identify the fault pole accurately varying fault resistance.

\subsection{Performance during grid side AC fault}

The AC fault at inverter end is the most common fault. But since the fault occurs in AC section of grid side both the poles are influenced and voltage signal increases in both poles. Different types of AC faults such as L-G, LL-G and LLL-G are studied. The voltage signals of P1 and P2 are shown by Fig. $6 a, b$ respectively during L-G fault at 40 $\mathrm{ms}$ in $\mathrm{AC}$ section. The AC voltage signals of grid side are shown in Fig. 6c. The fault detection output $D$ is shown in Fig. $6 \mathrm{~d}$ which shows that there is no fault in the system. Hence the relay at the rectifier end do not trip for DC section during $\mathrm{AC}$ faults. The most severe type of fault

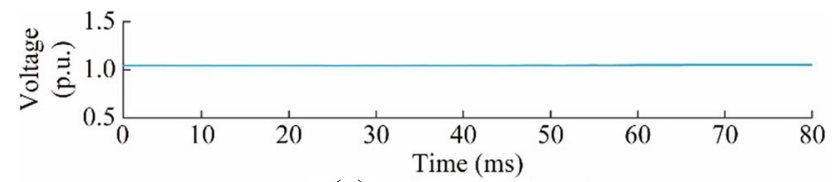

(a) Voltage signal in P1

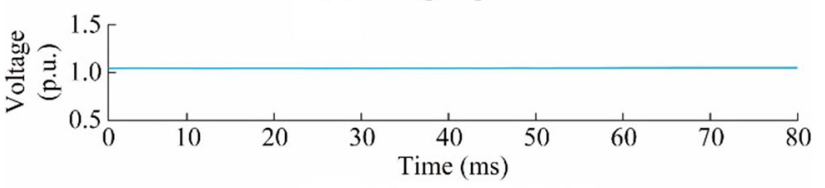

(b) Voltage signal in P2

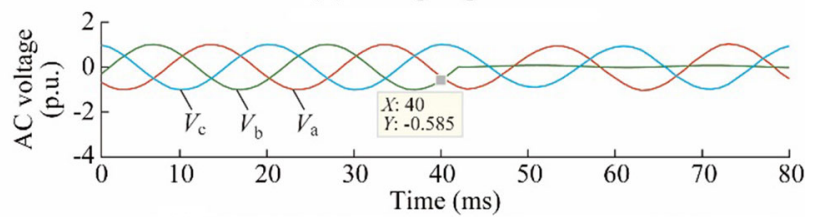

(c) Grid side AC voltage under line to ground fault

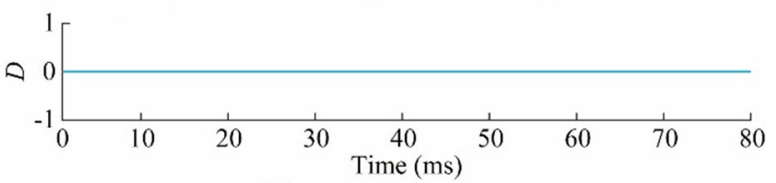

(d) Fault detection output

Fig. 6 Voltage signals, grid side AC voltage, fault detection output during line to ground for fault with the resistance of $0 \Omega$ at $40 \mathrm{~ms}$ in AC section called LLL-G fault also have no influence on the relay at rectifier end. Some of the test results are given in Table 5 for AC faults. The proposed method discriminates the AC faults correctly.

\subsection{Performance during fault in wind farm side}

Proposed method is tested with AC section fault near wind farm side. L-G fault is shown in Fig. 7 which occurs at $40 \mathrm{~ms}$ in $\mathrm{AC}$ section with $0 \Omega$ fault resistance. The voltage signals of pole 1 and pole 2 are shown in Fig. $7 \mathrm{a}, \mathrm{b}$ respectively. The waveforms of AC voltages for L-G fault are shown in Fig. 7c. Figure 7d shows the output of fault detection which is ' 1 ' shows there is fault in the system. Figure $7 \mathrm{~d}$ shows the output of fault detection which is ' 1 ' after $17 \mathrm{~ms}$ shows there is fault in the system. But the fault is external since there is decrease in voltage in both poles

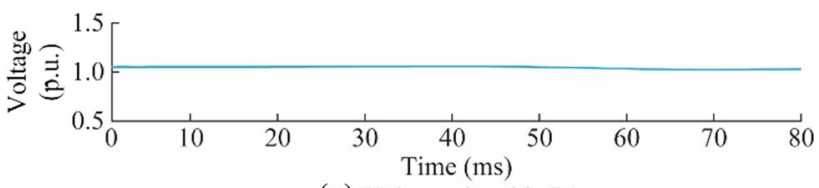

(a) Voltage signal in P1

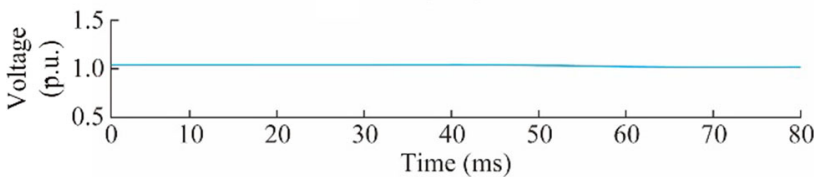

(b) Voltage signal in P2

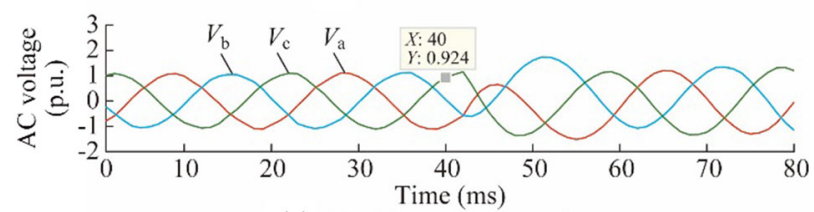

(c) Wind farm side AC voltage

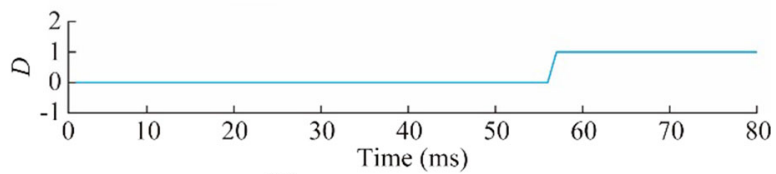

(d) Fault detection output

Fig. 7 Voltage signal, wind farm side AC voltage, fault detection output during LG fault with resistance of $0 \Omega$ at $40 \mathrm{~ms}$ in AC section

Table 5 Performance varying grid side AC faults

\begin{tabular}{|c|c|c|c|c|c|c|c|c|}
\hline \multirow[t]{2}{*}{ Fault type and position $(\mathrm{km})$} & \multirow[t]{2}{*}{$R_{\mathrm{f}}(\Omega)$} & \multicolumn{2}{|c|}{ Fault detection } & \multicolumn{2}{|l|}{ S1 } & \multicolumn{2}{|l|}{ S2 } & \multirow[t]{2}{*}{ Identification } \\
\hline & & Output & Time (ms) & Output & Time (ms) & Output & Time (ms) & \\
\hline No fault & & 0 & - & - & - & - & - & - \\
\hline Grid side fault ((L-G) & 10 & 0 & 0 & 0 & 0 & 0 & - & External fault \\
\hline Grid side fault (L-G) & 20 & 0 & 0 & 0 & - & 0 & - & External fault \\
\hline Grid side fault (LLL-G) & 0 & 0 & 0 & 0 & - & 0 & - & External fault \\
\hline Grid side fault (LLL-G) & 10 & 0 & 0 & 0 & - & 0 & - & External fault \\
\hline
\end{tabular}


in similar manner. Figure 8 shows the most severe LLL-G fault at wind farm side at $40 \mathrm{~ms}$ with $0 \Omega$ fault resistance. The voltage signals of P1 and P2 are shown in Fig. 8a, b respectively. Fault detection output is shown in Fig. 8c. Fault section identification output is shown in Fig. 8d. AC section output ' $\mathrm{S} 2$ ' is ' -1 ' as shown in Fig. $8 \mathrm{~d}$ indicated the fault is external. Relay does not trip as the fault is detected as external. Some of the test results under varying fault resistance in wind farm side are shown in Table 6. L-G fault has less influenced on fault poles so detection and section identification time is more than severe fault. Hence

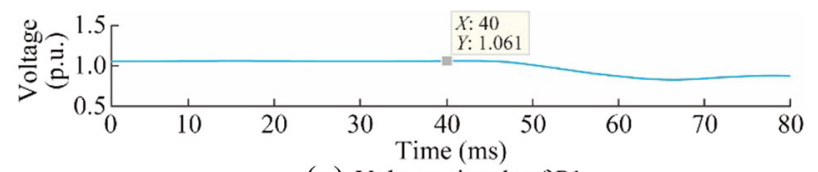

(a) Voltage signals of P1

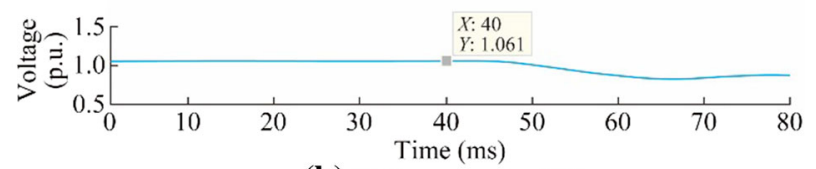

(b) Voltage signals of P2

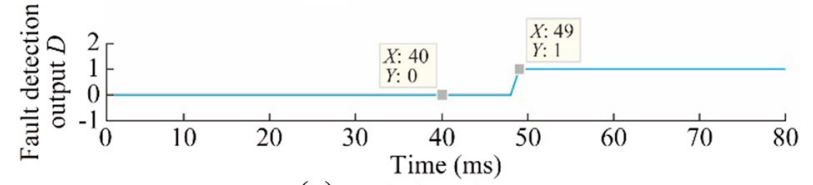

(c) Fault detection output

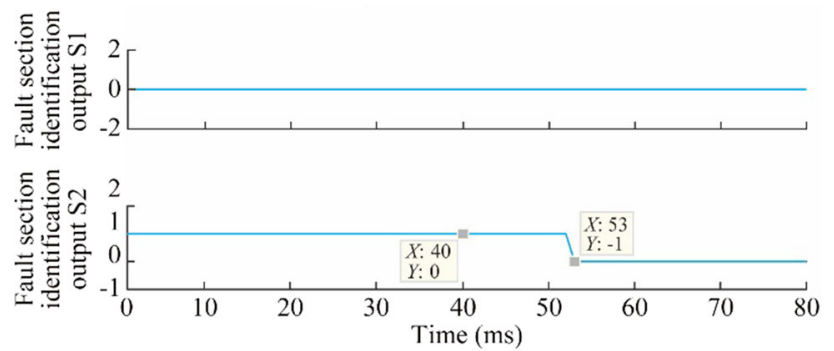

(d) Fault section identification output of S1 and S2

Fig. 8 Voltage signal and fault section identification output during three phases line to ground (LLL-G) fault in wind farm side with $0 \Omega$ at $40 \mathrm{~ms}$ the proposed method identifies wind farm side as external faults accurately.

\subsection{Comparison with other schemes}

The proposed fuzzy based method has been compared with other similar work in terms of number of relays used, sampling frequency and fault section identification. The comparison of various techniques has been shown in Table 7. It can be observed that other methods have used more relays for protection task as compare to proposed method. Hence other method requires time for relay coordination while proposed method does not. The sampling frequency require for proposed method is far more less than the other methods. Fault section identification has not been carried out by some of the method. Considering all the factors proposed relay seems better to use in power system applications.

\subsection{Advantages and novelty of the scheme}

The proposed fuzzy based methods are effective as wind energy is gaining popularity in power sector. The novelty and advantages of the proposed method can be outlined as follows:

1) The novelty of the proposed method is that it uses only one relay to identify the internal faults and external faults.

2) The novelty of the proposed method is that it can identify the section during severe AC faults (LLL and LLL-G) with $0 \Omega$ fault resistance.

3) The novelty of the proposed method is that it has reach setting of $99.8 \%$ of the line length (0 to $300 \mathrm{~km}$ transmission line).

4) The novelty of the proposed method is that it uses very low sampling frequency $(1 \mathrm{kHz})$ which is easy to realize.

5) The novelty of the proposed method is that it used same membership function with different rules to detect fault, identify fault section and classify faults.

Table 6 Performance varying fault at wind farm side

\begin{tabular}{|c|c|c|c|c|c|c|c|c|}
\hline \multirow[t]{2}{*}{ Fault type and position $(\mathrm{km})$} & \multirow[t]{2}{*}{$R_{\mathrm{f}}(\Omega)$} & \multicolumn{2}{|c|}{ Fault detection } & \multicolumn{2}{|l|}{ S1 } & \multicolumn{2}{|l|}{ S2 } & \multirow[t]{2}{*}{ Identification } \\
\hline & & Output & Time (ms) & Output & Time (ms) & Output & Time (ms) & \\
\hline No fault & & 0 & - & - & - & - & - & - \\
\hline L-G & 10 & 0 & 0 & 0 & - & 0 & - & External fault \\
\hline L-G & 20 & 0 & 0 & 0 & - & 0 & - & External fault \\
\hline LLL-G & 10 & 1 & 9 & 0 & - & -1 & 13 & External fault \\
\hline LLL-G & 20 & 0 & 11 & 0 & - & -1 & 15 & External fault \\
\hline LLL-G & 100 & 0 & 0 & 0 & - & 0 & 0 & External fault \\
\hline
\end{tabular}


Table 7 Comparison with other methods

\begin{tabular}{|c|c|c|c|c|c|c|}
\hline Authors & $\begin{array}{l}\text { Fault } \\
\text { resistance }(\Omega)\end{array}$ & $\begin{array}{l}\text { Relay } 1 \text { (primary) } \\
\text { location }\end{array}$ & $\begin{array}{l}\text { Relay } 2 \text { (backup) } \\
\text { location }\end{array}$ & $\begin{array}{l}\text { Relay } 3 \text { (backup) } \\
\text { location }\end{array}$ & $\begin{array}{l}\text { Sampling } \\
\text { frequency }(\mathrm{kHz})\end{array}$ & Section discrimination \\
\hline $\mathrm{J}$ Liu et al & 300 & $\begin{array}{l}\text { Yes (at one end of } \\
\text { line) }\end{array}$ & $\begin{array}{l}\text { Yes (at other end of } \\
\text { line) }\end{array}$ & - & 10 & Yes \\
\hline $\begin{array}{l}\text { J Sneath } \\
\text { et al }\end{array}$ & - & Yes (bus side) & Yes (line side) & - & - & Partly \\
\hline $\begin{array}{l}\text { R Irnawan } \\
\text { et al }\end{array}$ & - & $\begin{array}{l}\text { Yes (at one end bus } \\
\text { side) }\end{array}$ & $\begin{array}{l}\text { Yes (at one end of } \\
\text { bus side) }\end{array}$ & $\begin{array}{l}\text { Yes (at one end of } \\
\text { bus side) }\end{array}$ & - & Partly \\
\hline Q Yang et al & 100 & $\begin{array}{l}\text { Yes (at one end of } \\
\text { line) }\end{array}$ & & & 10 & Yes \\
\hline $\begin{array}{l}\text { C Petino } \\
\text { et al }\end{array}$ & - & $\begin{array}{l}\text { Yes (at one end of } \\
\text { line) }\end{array}$ & $\begin{array}{l}\text { Yes (at one end of } \\
\text { line) }\end{array}$ & $\begin{array}{l}\text { Yes (at one end of } \\
\text { line) }\end{array}$ & - & - \\
\hline $\begin{array}{l}\text { A Sajadi } \\
\text { et al }\end{array}$ & - & $\begin{array}{l}\text { Yes (at one end of } \\
\text { line) }\end{array}$ & $\begin{array}{l}\text { Yes (at one end of } \\
\text { line) }\end{array}$ & - & - & - \\
\hline $\begin{array}{l}\text { M Baran } \\
\text { et al }\end{array}$ & - & $\begin{array}{l}\text { Yes (at one end of } \\
\text { line) }\end{array}$ & $\begin{array}{l}\text { Yes (at one end of } \\
\text { line) }\end{array}$ & $\begin{array}{l}\text { Yes (at other end of } \\
\text { line) }\end{array}$ & - & Yes \\
\hline $\mathrm{J}$ Yang et al & 0.5 & $\begin{array}{l}\text { Yes (at one end of } \\
\text { line) }\end{array}$ & $\begin{array}{l}\text { Yes (at one end of } \\
\text { line) }\end{array}$ & - & - & Yes \\
\hline X Chu et al & 200 & $\begin{array}{l}\text { Yes (at one end of } \\
\text { line) }\end{array}$ & $\begin{array}{l}\text { Yes (at one end of } \\
\text { line) }\end{array}$ & - & 10 & Yes \\
\hline $\begin{array}{l}\text { C Ricardo } \\
\text { et al }\end{array}$ & 100 & $\begin{array}{l}\text { Yes (at one end of } \\
\text { line) }\end{array}$ & $\begin{array}{l}\text { Yes (at one end of } \\
\text { line) }\end{array}$ & $\begin{array}{l}\text { Yes (at other end of } \\
\text { line) }\end{array}$ & 4 & Yes \\
\hline $\mathrm{Z}$ He et al & 300 & $\begin{array}{l}\text { Yes (at one end of } \\
\text { line) }\end{array}$ & $\begin{array}{l}\text { Yes (at one end of } \\
\text { line) }\end{array}$ & - & 100 & Yes \\
\hline $\begin{array}{l}\text { N Geddada } \\
\text { et al }\end{array}$ & 40 & $\begin{array}{l}\text { Yes (at one end of } \\
\text { line) }\end{array}$ & $\begin{array}{l}\text { Yes (at one end of } \\
\text { line) }\end{array}$ & - & 10 & Yes \\
\hline $\begin{array}{l}\text { Shilong L, } \\
\text { et al }\end{array}$ & 50 & $\begin{array}{l}\text { Yes (at one end of } \\
\text { line) }\end{array}$ & $\begin{array}{l}\text { Yes (at one end of } \\
\text { line) }\end{array}$ & - & - & Yes \\
\hline Yeap, et al & 500 & $\begin{array}{l}\text { Yes (at one end of } \\
\text { line) }\end{array}$ & $\begin{array}{l}\text { Yes (at one end of } \\
\text { line) }\end{array}$ & - & 15.36 & Yes \\
\hline $\begin{array}{l}\text { Proposed } \\
\text { method }\end{array}$ & 300 & $\begin{array}{l}\text { Yes (at one end of } \\
\text { line) }\end{array}$ & - & - & 1 & Yes \\
\hline
\end{tabular}

6) The novelty of the proposed method is that it used only one relay, therefore time delay due to coordination between the relay has been avoided.

7) The proposed method discriminates the AC faults in grid side from DC faults with $100 \%$ accuracy.

8) The proposed method discriminates metallic faults in wind farm side with $100 \%$ accuracy.

9) Internal faults as high as $300 \Omega$ resistance are identified and discriminated from AC faults.

10) It requires data from one end hence avoids communication requirements.

11) The method is implemented only on voltage signal. It has an added advantage that the scheme will not be influenced by reversal of power which is due to reversal of current.

\section{Conclusion}

In this work a fuzzy based method is proposed for onshore wind firm integrated VSC-HVDC transmission lines. Previously suggested methods suffer from more computation requirements, a greater number of protection relays whose functioning depends on different signals, complexity and require signal requirements from both ends of the line. The proposed method has added advantages over other complex methods. Proposed method has few simple rules which make less requirement of memory and computation time. Proposed method is implemented using only one relay which avoids delay require for coordination of relays. Another advantage of proposed method is that discriminates AC and DC section faults with $100 \%$ accuracy. Yet another advantage of proposed method is that the faults in one section does not cause mal-operation of the relay and change in power capability of the lines. With the increased requirements of wind energy and multi-terminal 
HVDC transmission lines the proposed method can be adopted effectively.

Open Access This article is distributed under the terms of the Creative Commons Attribution 4.0 International License (http:// creativecommons.org/licenses/by/4.0/), which permits unrestricted use, distribution, and reproduction in any medium, provided you give appropriate credit to the original author(s) and the source, provide a link to the Creative Commons license, and indicate if changes were made.

\section{References}

[1] Bresesti P, Kling WL, Hendriks RL et al (2007) HVDC connection of offshore wind farms to the transmission system. IEEE Trans Energy Convers 22(1):37-43

[2] Meyer C, Hoing M, Peterson A et al (2007) Control and design of DC grids for offshore wind farms. IEEE Trans Ind Appl 43(6): 1475-1482

[3] Bozhko S, Asher G, Li R et al (2008) Large offshore DFIGbased wind farm with line-commutated HVDC connection to the main grid: engineering studies. IEEE Trans Energy Convers 23(1):119-126

[4] ABB (2009) Grid connection of off_shore wind farms BorWin1. www.abb.com/hvdc

[5] Asplund G (2009) HVDC grids possibilities and challenges. CIGRE SC B4 Bergen Colloq, Norway

[6] Round 3 (2008) Offshore wind farm connection study senergy econnect and national grid. Crown Estate Rep

[7] Noro Y, Arai J, Tagaki K et al (2002) System study of direct current power transmission system connected to a wind farm. In: Proceedings of IEEE PES transmission and distribution conference exhibition, Yokohama, Japan, 6-10 October 2002, 6 pp

[8] Perveen R, Kishor N, Mohanty SR et al (2015) Fault detection for offshore wind farm connected to onshore grid via voltage source converter-high voltage direct current. IET Gener Transm Distrib 9(16):2544-2554

[9] Vrionis TD, Koutiva XI, Vovos NA et al (2007) Control of an HVDC link connecting a wind farm to the grid for fault ride through enhancement. IEEE Trans Power Syst 22(4):2039-2047

[10] Feltes C, Wrede H, Koch FW et al (2009) Enhanced fault ride through method for wind farms connected to the grid through VSC-based HVDC transmission. IEEE Trans Power Syst 24(3):1537-1546

[11] Xu L, Yao L, Sasse C et al (2007) Grid integration of large DFIG-based wind farms using VSC transmission. IEEE Trans Power Syst 22(3):976-984

[12] Deng F, Chen Z (2013) Operation and control of a DC-grid offshore wind farm under transmission system faults. IEEE Trans Power Del 28(3):1356-1363

[13] Jovcic D (2008) Offshore wind farm with a series multiterminal CSI HVDC. Electr Power Syst Res 78(4):747-755

[14] Gomis-Bellmunt O, Liang J, Ekanayake J et al (2011) Topologies of multiterminal HVDC-VSC transmission for large offshore wind farms. Electr Power Syst Res 88(2):271-281

[15] Kirakosyan A, Mohamed SEM, Khadkikar V et al (2017) Fault ride through and grid support topology for the VSC-HVDC connected offshore wind farms. IEEE Trans Power Del 32(3):1592-1604

[16] Nanou SI, Papathanassiou SA (2016) Grid code compatibility of VSC-HVDC connected offshore wind turbines employing power synchronization control. IEEE Trans Power Syst 31(6):5042-5050
[17] Wu J, Li H, Wang G et al (2017) An improved traveling-wave protection scheme for LCC-HVDC transmission lines. IEEE Trans Power Del 32(1):106-116

[18] Johnson JM, Yadav A (2017) Complete protection scheme for fault detection classification and location estimation in HVDC transmission lines using support vector machines. IET Sci Meas Technol 11(3):279-287

[19] Agarwal S, Swetapadma A, Panigrahi CK et al (2017) An improved method using artificial neural network for fault detection and fault pole identification in voltage source converter-based high-voltage direct current transmission lines. Arab J Sci Eng 4:1-14

[20] Yadav A, Swetapadma A (2014) Improved first zone reach setting of artificial neural network-based directional relay for protection of double circuit transmission lines. IET Gen Trans Distrib 8(3):373-388

[21] Yadav A, Swetapadma A (2016) A finite-state machine based approach for fault detection and classification in transmission lines. Electr Mach Power Syst 44(1):43-59

[22] Xu L, Ya Y (2011) DC voltage control and power dispatch of a multi-terminal HVDC system for integrating large offshore wind farms. IET Renew Power Gener 5(3):223-233

[23] Abu-Elanien A, Elserougi A, Abdel-Khalik M et al (2016) Differential protection technique for multi-terminal HVDC. Electr Power Syst Res 130:78-88

[24] Hur N, Jung J, Nam K et al (2001) A fast dynamic DC-link power-balancing scheme for a PWM converter-inverter system. IEEE Trans Ind Electron 48(4):794-803

[25] Lianwei J, Boon-Teck O, Geza J et al (2005) Doubly-fed induction generator (DFIG) as a hybrid of asynchronous and synchronous machines. Electr Power Syst Res 76(3):33-37

[26] Pena R, Clare JC, Asher GM (1996) Double fed induction generator using back-to-back PWM converter and its application to variable speed wind-energy generation. Electr Power Appl 143(3):231-241

[27] Liu J, Tai N, Fan C et al (2017) Transient-voltage-based protection scheme for DC line faults in the multi-terminal VSCHVDC system. IEEE Trans Power Del 32(3):1483-1493

[28] Sneath J, Rajapakse A (2016) Fault dtection and iterruption in an erthed HVDC grid using ROCOV and hybrid DC breakers. IEEE Trans Power Del 31(3):973-981

[29] Sajadi A, Strezoski L, Clark K et al (2018) Transmission system protection screening for integration of offshore wind power plants. Renew Energy 125:225-233

[30] Yang Q, Blond S, Aggarwal R et al (2017) New ANN method for multi-terminal HVDC protection relaying. Electr Power Syst Res 148:192-201

[31] Petino C, Heidemann M, Eichhoff D et al (2016) Application of multilevel full bridge converters in HVDC multiterminal systems. IET Power Electron 9(2):297-304

[32] Baran M, Mahajan N (2007) Overcurrent protection on voltagesource-converter-based multiterminal DC distribution systems. IEEE Trans Power Del 22(1):406-412

[33] Yang J, Fletcher J, O'Reilly J et al (2010) Multiterminal DC wind farm collection grid internal fault analysis and protection design. IEEE Trans Power Del 25(4):2308-2318

[34] Hernandez J, Sanchez SF, Gomez P et al (2016) Protection of a multiterminal DC compact node feeding electric vehicles on electric railway systems, secondary distribution networks, and PV systems. Turk J Electr Eng Co Sc 24(4):3123-3143

[35] Chu X, Song G (2016) Analytical method of fault characteristic and non-unit protection for HVDC transmission lines. CSEE J Power Energy Syst 2(4):37-43

[36] Santosa R, Blondb SL, Couryc D et al (2016) A novel and comprehensive single terminal ANN based decision support for 
relaying of VSC based HVDC links. Electr Power Syst Res 141:333-343

[37] He Z, Liao K (2015) Natural frequency-based protection scheme for voltage source converter-based high voltage direct current transmission lines. IET Gener Trans Distrib 9(130):1519-1525

[38] Geddada N, Yeap Y, Ukil A (2018) Experimental validation of fault identification in VSC-based DC grid system. IEEE Trans Ind Electron 65(6):4799-4808

[39] Li S, Chen W, Yin X et al (2017) Protection scheme for VSCHVDC transmission lines based on transverse differential current. IET Gener Transm Distrib 11(11):2805-2813

[40] Yeap Y, Geddada N, Ukil A (2017) Analysis and validation of wavelet transform based DC fault detection in HVDC system. Appl Soft Comput 61:17-29

[41] Wang Y, Zhang Z, Fu Y et al (2016) Pole-to-ground fault analysis in transmission line of DC grids based on VSC. In: Proceedings of IEEE 8th international power electronics and motion control conference, Hefei, China, 22-26 May 2016, 5 pp

Shobha AGARWAL received her B.Tech. degree from NIT Patna and M.Tech. degree from IIT Delhi. She is presently working as Assistant Professor in KIIT university and Ph.D. research scholar in school of Electrical Engineering, KIIT University, Bhubanswar. She has published a number of papers in conferences and journal related to HVDC protection.
Aleena SWETAPADMA received her B.Tech. degree from CET, Bhubaneswar, India (2007-2011), M.Tech. degree from NIT, Raipur, India (2011-2013) and Ph.D. degree from NIT, Raipur, India (2013-2016). She is with School of Computer Engineering, KIIT University, Bhubaneswar, India as faculty member from 2016. Her field of interest includes power system protection, HVDC, FACTS and artificial intelligence applications. She received POSOCO power system award for M.Tech. thesis (2014) and Ph.D. thesis (2017) from POSOCO, India.

Chinmoy Kumar PANIGRAHI received his B.Tech. and M.Tech. degrees from Sambalpur University. He received the Ph.D. degree from Jadavpur University in power system Engineering and has guided many research scholars in the field of smart grid, HVDC, FACTS. He is presently working as Dean in School of Electrical Engineering, KIIT university, and has published a number of papers in conferences and journal.

Abhijit DASGUPTA has 21 years of industrial experience and 14 years of academic experience. Presently he is a professor in School of Electrical Engineering, KIIT University, Bhubaneswar, India. He has authored many research papers in the areas of power electronics, automatic generation control, and implementation of new optimization techniques. 